Ivana D. Atanasovska

Katica R. (Stevanovic) Hedrih

https://doi.org/10.21278/TOF.42201

ISSN 1333-1124

eISSN 1849-1391

\title{
A NEW COLLISION MODEL FOR ANALYSING THE VIBRO-IMPACT OF SPUR GEARS
}

\begin{abstract}
Summary
A model of a central centric collision of two fictive rolling disks, with radii equal to the radii of pitch diameters of coupled gears, is used to describe the vibro-impact dynamics of spur gears.

Total deformations vary during the operation of spur gears with involute profile, particularly as a result of variable number of pairs of teeth in contact. These variations, as well as tooth profile misalignments or damages, lead to the backlash, the appearance of internal dynamic forces, and impact. Particular values of tooth profile parameters and transmission ratio create the conditions for a vibro-impact vibration regime. The vibro-impact gear dynamics is characterized by vibro-impact vibrations in the contact between the pinion tooth and the wheel tooth during a short period of time after the collision.

New formulas for the calculation of the time periods between two tooth collisions, as well as between two successive tooth collision impacts, are devised. Also, a set of equations for the calculation of the disturbance angular velocity of the pinion called the transmission error is developed; the transmission error has a role of an excitation for vibro-impact vibrations in the gear tooth contact.
\end{abstract}

Key words: $\quad$ Spur gears, vibro-impact, collision, coefficient of restitution, angular velocity

\section{Introduction}

Gears are most widely used devices for the transmission of rotary motion from one shaft to another and they can be found in all kinds of machinery. It is very important to develop a reliable model to simulate the dynamic/impact behaviour of gear sets as it could have a wide range of applications in the optimization of gear parameters.

In real operating conditions, the gear teeth and the gear bulks are elastic bodies with standard allowed deviations from the standard shape and dimensions. That leads to the variations in the real transmission ratio around the constant theoretical value and to the appearance of a dynamic transmission error. As a result of elastic deformations of the teeth in contact and the above mentioned manufacturing deviations, the drive gear (the pinion in a spur gear pair) has an angular clearance (backlash) with respect to the driven gear (the wheel in a spur gear pair). 
If the normal load on tooth flanks in contact were constant during the gear pair operation, or if it were possible to always have only one pair of teeth in contact, the total deformation of the pair of teeth in contact would remain nearly unchanged. However, the number of pairs of teeth which are simultaneously in contact changes during the gear pair meshing. During the operation of cylindrical involute gears with straight teeth (spur gears), the period with a single pair of teeth in contact alternates with that with a double pair of teeth in contact. When the period with a single pair of teeth in contact ends and the period with two teeth pairs in contact starts, the normal load on the flanks of the previous pair of meshed teeth decreases; therefore, the contact and the bending deformations on this pair of teeth also decrease. This change happens during a very short time period and its consequence is the appearance of internal dynamic forces that cause the impact phenomenon. The similar phenomenon occurs when the period with two pairs of teeth in contact end and the period with a single pair of teeth in contact starts. In the same way, the deviations of the tooth profile pitch of the pinion and of the wheel could cause internal dynamic forces and, consequently, impacts. It should be noted that these deviations can be positive or negative values.

Extensive research into the gear vibration and other dynamic phenomena has been done in last few decades. There are a lot of papers published describing models and procedures which attempted to explain some or all of the aspects of gear dynamics. Spitas and Spitas [1] give a comprehensive review of published research in this area. Almost all of analyses in the conducted research used the equation of motion to explain the gear pair as a multi-DOF (degrees of freedom) dynamic system. However, a significant number of authors verified a hypothesis that a reduction of the system to a two [2] or to a single degree of freedom system [3-7] will not reduce the quality of a model but that it will simplify numerical operations and enable a wider range of applications. Vibration of a spur gear pair in all of the mentioned models was simulated by two disks coupled by nonlinear mesh stiffness/mesh damping and excitation due to gear errors, [2-4, 6-10]. A number of authors use the Finite Element Method (FEM) within their gear dynamic models for the calculation of meshed gear teeth deformations and stiffness function, [5-7, 11-12]; they found out that this numerical method gave excellent results for those purposes. Moradi and Salarieh described a dynamic system of a spur gear pair that could be reduced to a single degree of freedom model in terms of dynamic transmission error [3]; they concluded that the approximation of the nonlinear backlash function with a third-order polynomial could lead to the methodology for studying the nonlinear dynamics of spur gears.

In this paper, a completely new and original application of the extension of the classical theory of impact with the theory of kinematics and dynamics of the collision of two rolling axially symmetric bodies was used for the investigation of a new model of vibro-impact dynamics of a spur gear pair [13-17]. The new model of vibro-impact dynamics of spur gears is described in detail in accordance with the main postulates of the model of the central centric collision of two fictive rolling disks, with radii equal to the radii of kinematic diameters of the pinion and the wheel and with the current rolling axes in collision which coincide with the rotation axis of the pinion and the wheel [13-17].

\section{A model for the vibro-impact dynamics of spur gears}

\subsection{Description of collision and vibro-impact phenomena in the contact between gear teeth}

Involute cylindrical gears are widely used, primarily due to the approximately constant transmission ratio, which is defined by the following relation:

$$
i=\frac{\omega_{1}}{\omega_{2}}=\frac{z_{2}}{z_{1}}=\frac{r_{2}}{r_{1}}
$$


where: $\omega_{1,2}$ is the angular velocity of the pinion (1) or the wheel (2), $z_{1,2}$ is the number of teeth of the pinion (1) or the wheel (2), $r_{1,2}$ is the reference radius of the pinion (1) or the wheel (2).

Vibro-impact dynamics occurs when disturbance of the angular velocity ratio occurs. The disturbance of angular velocity of the pinion is defined as:

$$
\Delta \omega_{1}=\omega_{1}-i \omega_{2}>0
$$

and could be considered as the excitation of vibro-impact vibrations. It is necessary to note that the conditions for the vibro-impact vibration regime of spur gear operation exist only in the special cases of involute cylindrical gears, and that the regime is characterized by the vibro-impact behaviour of the pinion gear. Whether the vibro-impact dynamics will occur in the coupling of a gear pair or not depends primarily on the gear geometry, i.e. on the tooth profile parameters and transmission ratio. These variables could have, in some cases, the values which lead to a very small arc distance between the pinion tooth and the next wheel tooth. As a result, at the moment of the change in the number of pairs of teeth in contact, the collision of the pinion tooth and the wheel tooth causes a backward rejection of the pinion tooth and its collision with the next wheel tooth. A number of successive forward-backward collisions-impacts occur during a very short time period and lead to a decrease in the disturbance of the post-collision outgoing and the next pre-collision arrival angular velocity. After a few successive forward-backward collisions-impacts, the regular operation regime returns and the gears rotate without vibro-impact vibrations. In the ideal stationary kinetic states, this phenomenon is repeated to infinity, and all of operation disturbances described have only the character of vibro-impact vibrations and not of permanent disorders of angular velocities. However, a certain amount of energy is lost in such cases.

The calculation of the disturbance of the pinion angular velocity is of main importance in the development of a model of vibro-impact oscillations of spur gears. The starting point can be the definition of the tooth profile pitch deviation as a result of deformations and manufacturing deviations, as:

$$
b=K_{b} m_{n}, \mathrm{~mm}
$$

where: $m_{n}$ is the standard normal tooth profile module, while $K_{b}$ could be defined as the error coefficient which has its value in the range 0.01-0.1, [2].

Then, the time which is required for a pinion tooth to pass this deviation can be expressed as:

$$
T(b)=\frac{K_{b} m_{n}}{r_{1}} \frac{1}{\omega_{1}}, \mathrm{~s}
$$

In the research presented in this paper, the vibro-impact of spur gears without any type of damage is analysed as a first step in the analysis of the new collision model.

The disturbance of the pinion angular velocity can be calculated in accordance with the postulate that the rotation time of the pinion gear will be the same in the cases with and without deviation $b$ :

$$
\frac{2 \pi}{\omega_{1}}=\frac{2 \pi+\frac{K_{b} m_{n}}{r_{1}}}{\omega_{1}+\Delta \omega_{1}}, \text { ie } \Delta \omega_{1}=\frac{K_{b} m_{n}}{2 \pi r_{1}} \omega_{1}, \mathrm{rad} / \mathrm{s}
$$

Coefficient $K_{b}$ in general depends on the variation in the total deformation of pairs of meshed teeth and on the deviation of base profile pitch. Variation in the total deformation $u_{s}$ during the contact period of a single pair of teeth is very small and could be calculated as a sum of deformation of the pinion tooth $u_{1}$, deformation of the wheel tooth $u_{2}$, and contact deformation $u_{H}$. The point of force action moves from the tooth root to the tooth addendum at 
the pinion gear tooth; therefore, the moment arm relative to the root increases and, consequently, deflection increases. This leads to an increase in the deformation of pinion tooth $u_{1}$. In contrast, the point of force action moves from the tooth tip to the tooth dedendum at the wheel gear tooth; therefore, the moment arm relative to the root decreases and, consequently, deflection decreases. This leads to a decrease in the deformation of the wheel tooth $u_{2}$ during the contact period. The local contact deformation of meshed tooth flanks $u_{H}$ is almost constant during the tooth pair contact. Therefore, if the normal force acting on tooth flanks is constant during the gear operation, i.e. if there is a single pair of teeth in contact during transmission, the total deformation will be approximately unchanged.

However, the number of tooth pairs in contact is changing during the gear operation. In such conditions, the deformation of the pinion tooth and the wheel tooth, as well as the total deformation of the tooth pair in contact, vary. Figure 1 shows the variation in the variables of deformations during the single contact period in the case without the profile pitch deviations, calculated for a particular gear pair by the Finite Element Analysis, [18]. The variable $y_{p} / p_{b}$ defines the contact point position $(P)$ on the path of contact as a distance from the first point of the path of contact relative to the base profile pitch of meshed gears $\left(p_{b}\right)$. The variations in the intensity of the normal contact force and in deformations when the base pitch deviation exists can be also calculated, [19].

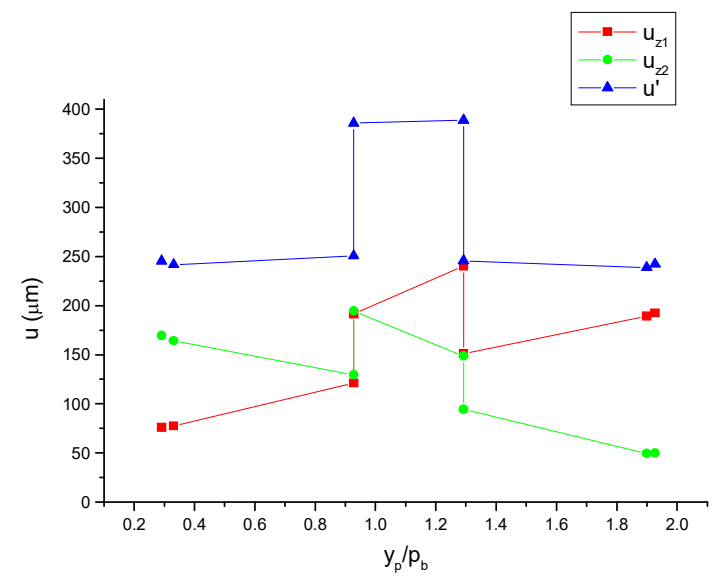

Fig. 1 Deformations along the line of action for a spur gear pair without pitch deviations

If the starting point of the analysis is the beginning of the gear pair operation when the wheel (driven gear) is stationary, then the total deformation of the starting meshing tooth pair causes a backward movement of the pinion (drive gear). This movement would lead to a pinion profile pitch reduction and a wheel profile pitch increase. From theoretical (geometric) point of view, the overlap of profile lines of the next tooth pair that should come in contact would occur. In real conditions, this leads to the collision of the pinion tooth dedendum with the tip of the wheel tooth of the next pair. In this way, the wheel accelerates and its delay with respect to the pinion decreases. This corresponds to the moment when the period of a single tooth pair ends and that of a double tooth pair starts. If the contact is ideally elastic, after the second backward collision-impact, the outgoing angular velocities of the pinion and the wheel will return to the values at the starting point of analysis. The same phenomenon occurs when the base pitch manufacturing deviation is less than 0, [18-19].

A similar analysis could be performed for the moment when the double tooth pair period passes and a single tooth pair period starts; at that moment, the single meshed tooth pair receives the full external load. This leads to a new collision. The wheel again delays with respect to the pinion as a result. The same phenomenon occurs when the base pitch manufacturing deviation is greater than $0,[18-19]$. As a result, vibro-impact vibrations of the gear pair would be generated. 
In the following consideration, we use the approximation of a gear pair using two fictive rolling disks with radii equal to the radii of pitch diameters of the pinion and the wheel. The influence of gear masses is taken into account by axial mass moments of inertia for the current gear axis of rotation. The angular velocities of the pinion and the wheel before and after every collision, and before and after every successive collision-impact, are calculated in accordance with the postulates of the extension of the classical theory of impact and collision of two rolling, axially symmetric rigid bodies, [13-17]. These velocities depend on the tooth profile pitch deviations as well as on the total deformation of a tooth pair. Values of the pinion tooth deformation, the wheel tooth deformation, and the total deformation of the tooth pair should be calculated precisely; for this reason, the Finite Element Analyses are performed using the models developed specially for that purpose, [18, 20-21].

\subsection{A model of the central centric collision of two rolling disks}

In any point $P$ with a character of vibro-impact vibration behaviour, two fictive rolling disks, used to simulate the tooth pair contact, represent a system with the rotation defined by the axial mass inertia moments $\mathbf{J}_{p 1}$ and $\mathbf{J}_{p 2}$ for the corresponding instantaneous axis of fictive rolling-rotation. In the point $\mathrm{P}$, these disks have the arrival (before-impact) angular velocities $\vec{\omega}_{P 1, \text { impact }}=\vec{\omega}_{P 1}\left(t_{0}\right)$ and $\vec{\omega}_{P 2, \text { impact }}=\vec{\omega}_{P 2}\left(t_{0}\right)$, and the corresponding outgoing (after-impact) angular velocities $\vec{\omega}_{P 1, \text { outgoing }}=\vec{\omega}_{P 1}\left(t_{0}+\tau\right)$ and $\vec{\omega}_{P 2, \text { outgoing }}=\vec{\omega}_{P 2}\left(t_{0}+\tau\right)$, [13-17].

A qualitative and a mathematical analogy between the relations correspond to the system of translational dynamics and central collision (impact) dynamics of two bodies in translation and the relations correspond to the system of rolling dynamics of two disks and the central collision (impact) dynamics of two rolling disks in rolling motion could be found. This is in accordance with Petrovic's theory of elements of mathematical phenomenology and phenomenological mappings [22-24] in the sections dealing with qualitative and mathematical analogies.

On the basis of the qualitative and mathematical analogies mentioned above, analogous kinetic parameters of these systems can be defined:

- The axial mass inertia moments $\mathbf{J}_{p 1}$ and $\mathbf{J}_{p 2}$ for the corresponding instantaneous axis of rolling-rotation of two bodies in collision during rolling motion are analogous to the masses $m_{1}$ and $m_{2}$ of two bodies in collision during translation, [13-17].

- Before-impact (arrival) angular velocities at a moment $t_{0}\left(\vec{\omega}_{P 1, \text { impact }}=\vec{\omega}_{P 1}\left(t_{0}\right)\right.$ and $\left.\vec{\omega}_{P 2 \text {,impact }}=\vec{\omega}_{P 2}\left(t_{0}\right)\right)$ of the rolling disks around the corresponding instantaneous axis are analogous to the corresponding before-impact velocities $\left(\vec{v}_{1}\left(t_{0}\right)\right.$ and $\left.\vec{v}_{2}\left(t_{0}\right)\right)$ of two bodies in translation at the moment before collision.

- After-impact (outgoing) angular velocities at a moment $t_{0}+\tau\left(\vec{\omega}_{P 1, \text { outgoing }}=\vec{\omega}_{P 1}\left(t_{0}+\tau\right)\right.$ and $\left.\vec{\omega}_{P 2, \text { outgoing }}=\vec{\omega}_{P 2}\left(t_{0}+\tau\right)\right)$ of the rolling disks are analogous to the corresponding after-impact (outgoing) velocities $\left(\vec{v}_{1}\left(t_{0}+\tau\right)\right.$ and $\left.\vec{v}_{2}\left(t_{0}+\tau\right)\right)$ of two bodies in translation at the moment before collision.

On the basis of Petrovic's theory [22 -24] and the qualitative and mathematical analogies, as well as on the basis of the hypothesis of conservation of linear momentum (impulse) before and after collision, which is valid for the impact dynamics of two bodies in translatory motion, an analogous hypothesis of conservation of the sum of angular momentum (moment of impulse) before and after collision for the impact dynamics of two disks in rolling motion is formulated by K. Hedrih [13-17] and is given by the following relation:

$$
\mathbf{J}_{P 1} \vec{\omega}_{P 1}\left(t_{0}\right)+\mathbf{J}_{P 2} \vec{\omega}_{P 2}\left(t_{0}\right)=\mathbf{J}_{P 1} \vec{\omega}_{P 1}\left(t_{0}+\tau\right)+\mathbf{J}_{P 2} \vec{\omega}_{P 2}\left(t_{0}+\tau\right)
$$


Consequently, a new definition of the coefficient of restitution of the collision of two rolling disks [24] can be expressed as a ratio between the differences of angular velocities of rolling disks before collision and after collision, [13-17] in the following form:

$$
k=\frac{\omega_{r}\left(t_{0}+\tau\right)}{\omega_{r}\left(t_{0}\right)}=\frac{\omega_{P 2}\left(t_{0}+\tau\right)-\omega_{P 1}\left(t_{0}+\tau\right)}{\omega_{P 1}\left(t_{0}\right)-\omega_{P 2}\left(t_{0}\right)}
$$

This coefficient of restitution of the collision of two rolling bodies is a real, dimensionless number whose value is between zero and one (0-1); it depends on the material of the bodies and can be determined experimentally, [25].

In accordance with relations (7) and (8), the expressions of after-collision outgoing angular velocities of rolling disks or balls can be expressed in the following forms [13-17]:

$$
\begin{aligned}
& \omega_{P 1}\left(t_{0}+\tau\right)=\omega_{P 1}\left(t_{0}\right)-\frac{1+k}{1+\frac{\mathbf{J}_{P 1}}{\mathbf{J}_{P 2}}}\left(\omega_{P 1}\left(t_{0}\right)-\omega_{P 2}\left(t_{0}\right)\right) \\
& \omega_{P 2}\left(t_{0}+\tau\right)=\omega_{P 2}\left(t_{0}\right)+\frac{1+k}{1+\frac{\mathbf{J}_{P 2}}{\mathbf{J}_{P 1}}}\left(\omega_{P 1}\left(t_{0}\right)-\omega_{P 2}\left(t_{0}\right)\right)
\end{aligned}
$$

\subsection{The calculation of time periods between collisions and successive collisions-impacts}

In order to define the points in which the collision occurs during the gear pair operation, the characteristic points on the line of action should be defined. These points correspond to the moments when the normal contact force acting on the meshed flanks changes its value, Fig. 2. Therefore, the characteristic points (the points on the line of action when the number of tooth pairs in contact changes) are: point A - the first point of a tooth pair contact at the moment when the previous tooth pair is still in contact; point B - the first point of the single pair period and the last point of the previous tooth pair contact; point $\mathrm{D}$ - the next tooth pair comes in contact and the period with two tooth pairs in contact starts; and $\mathrm{E}$ - the last point of the tooth pair contact period and the first point of the single contact period for the tooth pair which came in contact at point D. It could be noticed that the point A for a particular tooth pair corresponds to the point $\mathrm{D}$ for the next teeth pair, and, in the same way, the point $\mathrm{E}$ for a particular tooth pair corresponds to the point B for the next tooth pair. Therefore, the following points should be analysed as the collision points (moments) during the rotation of gears:

- point A - when a tooth pair comes in contact and it could be approximately assumed that the tooth pair receives and transmits half of the total normal contact force $F_{b n} / 2$

- point $\mathrm{B}$ - when the same tooth pair receives and transmits the full total normal contact force because the previous tooth pair comes out of contact.

The distance between the collision points (A and B) can be calculated by the following relations:

$$
\begin{aligned}
& \overline{\mathrm{AB}}=\mathrm{g}_{\alpha}-\mathrm{p}_{\mathrm{e}}=\frac{1}{2}\left(\sqrt{\mathrm{d}_{\mathrm{a} 1}^{2}-\mathrm{d}_{\mathrm{b} 1}^{2}}+\sqrt{\mathrm{d}_{\mathrm{a} 2}^{2}-\mathrm{d}_{\mathrm{b} 2}^{2}}\right)-\mathrm{a} \sin \alpha_{\mathrm{w}}-\mathrm{m} \pi \cos \alpha_{\mathrm{w}} \\
& \overline{\mathrm{BD}}=\overline{\mathrm{BA}}=\mathrm{p}_{\mathrm{e}}-\overline{\mathrm{AB}}=2 \mathrm{~m} \pi \cos \alpha_{\mathrm{w}}- \\
& -\frac{1}{2}\left(\sqrt{\mathrm{d}_{\mathrm{a} 1}^{2}-\mathrm{d}_{\mathrm{b} 1}^{2}}+\sqrt{\mathrm{d}_{\mathrm{a} 2}^{2}-\mathrm{d}_{\mathrm{b} 2}^{2}}\right)+\mathrm{a} \sin \alpha_{\mathrm{w}}
\end{aligned}
$$


where: $g_{\alpha}=\frac{1}{2}\left(\sqrt{d_{a 1}^{2}-d_{b 1}^{2}}+\sqrt{d_{a 2}^{2}-d_{b 2}^{2}}\right)-a \sin \alpha_{w}-$ is the length of the line of action [26]; $p_{b}=p_{e}=m \pi \cos \alpha-$ is the base profile pitch;

$p_{e}$ is the arched profile pitch defined by the distance between the same points on the profiles of two adjacent gear teeth;

$d_{a 1,2}$ is the tip diameter of the pinion (1) or the wheel (2);

$d_{b 1,2}$ is the base diameter of the pinion (1) or the wheel (2);

$a$ is the gear axis distance;

$m$ is the normal module;

$\alpha$ is the angle of tooth involute profile, and

$\alpha_{w}$ is the angle of line of action, [26].

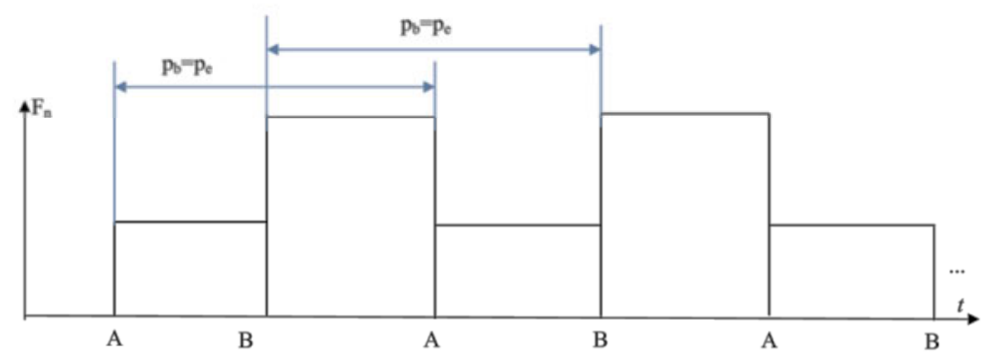

Fig. 2 Characteristic points corresponding to collision occurrences

Then, by applying the relations $i=\frac{\omega_{1}}{\omega_{2}}=\frac{r_{w 2}}{r_{w 1}}=\frac{r_{2}}{r_{1}}=\frac{z_{2}}{z_{1}}$ for the transmission ratio, $\varepsilon_{\alpha}=\frac{g_{\alpha}}{p_{b}}$ for the contact ratio, and $T_{1}{ }^{\prime \prime}=T_{1}{ }^{\prime} \frac{p_{e}}{p}=T_{1}{ }^{\prime} \frac{m \pi \cos \alpha}{m \pi}=T_{1}{ }^{\prime} \cos \alpha=\frac{2 \pi \cos \alpha}{z_{1} \omega_{1}}$ for the time period corresponding to the arched profile pitch, the formulae for the calculation of the time periods between tooth collisions have been derived:

$$
\begin{aligned}
& \mathrm{T}_{1}{ }^{\prime \prime}(\overline{\mathrm{AB}})=\mathrm{T}\left(\mathrm{g}_{\alpha}\right)-\mathrm{T}\left(\mathrm{p}_{\mathrm{e}}\right)=\mathrm{T}\left(\varepsilon_{\alpha} \mathrm{p}_{\mathrm{e}}\right)-\mathrm{T}\left(\mathrm{p}_{\mathrm{e}}\right)=\varepsilon_{\alpha} \mathrm{T}\left(\mathrm{p}_{\mathrm{e}}\right)-\mathrm{T}\left(\mathrm{p}_{\mathrm{e}}\right)=\frac{2 \pi \cos \alpha}{\mathrm{z}_{1} \omega_{1}}\left(\varepsilon_{\alpha}-1\right) \\
& \mathrm{T}_{1}{ }^{\prime}(\overline{\mathrm{BA}})=\mathrm{T}\left(\mathrm{p}_{\mathrm{e}}\right)-\mathrm{T}(\overline{\mathrm{AB}})=\frac{2 \pi \cos \alpha}{\mathrm{z}_{1} \omega_{1}}-\frac{2 \pi \cos \alpha}{\mathrm{z}_{1} \omega_{1}}\left(\varepsilon_{\alpha}-1\right)=\frac{2 \pi \cos \alpha}{\mathrm{z}_{1} \omega_{1}}\left(2-\varepsilon_{\alpha}\right)
\end{aligned}
$$

The time periods between successive collisions-impacts after the collision in every collision point along the line of action depend on the arcs corresponding to the distances between the teeth $\left(\alpha_{A}\right.$ and $\left.\alpha_{B}\right)$, which are determined by the base involute profile parameters, i.e. the profile modification (shift) coefficients $x_{1,2}$ and the angle of involute profile $\alpha$. For the calculation of the time periods between tooth successive impacts after the collision, the following relations are derived taking into consideration the disturbance of angular velocity defined by relation (5). Therefore, the final forms of the formulae obtained for these time periods are given as:

$$
\mathrm{t}\left(\alpha_{\mathrm{A}}\right)=\frac{\alpha_{\mathrm{A}} \frac{\pi}{180}}{\omega_{1}+\Delta \omega_{1}} ; \mathrm{t}\left(\alpha_{\mathrm{B}}\right)=\frac{\alpha_{\mathrm{B}} \frac{\pi}{180}}{\omega_{1}+\Delta \omega_{1}}
$$

\section{Vibro-impact vibrations of a gear pair - case study}

The model of vibro-impact vibrations of spur gears described above is demonstrated on a particular spur gear pair which has been chosen from a series of spur gears; the main characteristics and dimensions of the gear pair are given in Table 1, [20]. This gear pair has the geometry characteristics which define such values of the arc distances between the pinion tooth in contact and the wheel tooth of the next tooth pair that is not yet in contact, which are small enough to lead to the vibro-impact vibration behaviour. In order to calculate the 
coefficient $K_{b}$, the total deformation variation along the line of action is calculated by Finite Element Analysis (FEA) performed for this spur gear pair [20]. The obtained results are shown in Fig. 1.

A case without pitch deviations of meshed tooth pairs and base profile pitch deviation is assumed. In accordance with the explained theoretical model of vibro-impact vibrations of spur gears, the disturbance of angular velocity defined by relation (5) has been calculated. Then, the time periods between tooth collisions as well as between tooth successive collisionimpacts after each collision have been calculated in accordance with relations (12-14). The new formulae are derived in accordance with the same assumptions. These values have been used for the calculation of angular velocities of the pinion and the wheel before and after every collision and before and after every successive collision-impact in accordance with the postulates of the extension of the classical theory of impact and collision of two rolling disks, given by expressions (8) and (9). The algorithm for the calculation of all main characteristic variables of vibro-impact oscillations of the spur gear pair (each outgoing and the next arrival angular velocities in successive forward-backward collisions, angular momentum, kinetic energy, and transmission ratio) is programmed in the MathCAD software. For the spur gear with characteristics given in Table 1, the obtained results for the variations in the wheel angular velocity, kinetic energy of the wheel, and the transmission ratio during two contact periods are given in Fig. 3. It is very easy to recognize the points A (the first and the third collision in Fig. 3) and points B (the second and the forth collision in Fig. 3) in these diagrams.

Table 1 Characteristics of a particular real spur gear pair

\begin{tabular}{|c|c|c|c|}
\hline Variable & \multicolumn{3}{|c|}{ Symbol and value } \\
\hline Number of teeth & $z_{1}=20 ; z_{2}=96$ & $z_{1}=20 ; z_{2}=80$ & $z_{1}=20 ; z_{2}=60$ \\
\hline Transmission ratio & $i=z_{2} / z_{1}=4.8$ & $i=z_{2} / z_{1}=4$ & $i=z_{2} / z_{1}=3$ \\
\hline $\begin{array}{c}\text { The coefficients of profile } \\
\text { modification }\end{array}$ & \multicolumn{3}{|c|}{$x_{1}=0.7 ; x_{2}=-0.2$} \\
\hline Gear face width & \multicolumn{3}{|c|}{$b=350 \mathrm{~mm}$} \\
\hline Profile module & \multicolumn{3}{|c|}{$m=m_{n}=24$} \\
\hline Rpm for the wheel & $n_{2}=4.1596 \mathrm{~min}^{-1}$ \\
\hline Wheel torque & \multicolumn{3}{|c|}{$T_{2}=2526.8 \mathrm{kNm}$} \\
\hline Material characteristics & $E=206000 \mathrm{~N} / \mathrm{mm}^{2} ; v=0,3$ \\
\hline
\end{tabular}

\section{Analysis by a variation in the coefficient of restitution of a collision}

The analysis has been performed for the main characteristics of the first spur gear pair given in Table 1 , with a constant transmission ratio of $i=4.8$. The variation in the coefficient of restitution of the collision has been performed within a range of values, from the value of an ideally elastic collision with $k=1$, through the value for steel of $k=5 / 9$ to the value of $k=1 / 2$. The constant contact ratio leads to the same time periods between tooth collisions and successive impacts as in the previous analysis. All the characteristic variables of vibro-impact oscillations of the spur gear pair (the pinion and wheel angular velocities, the pinion and wheel angular momentum, kinetic energy of the pinion and the wheel, and the transmission ratio) are calculated by means of a theoretical model programmed in MathCAD; the appropriate comparative diagrams have been created for the previously mentioned three values of coefficient of restitution. The angular momentums are calculated as the products of the corresponding moments of inertia and angular velocities. The obtained results are shown in Figures 4 - 7. 


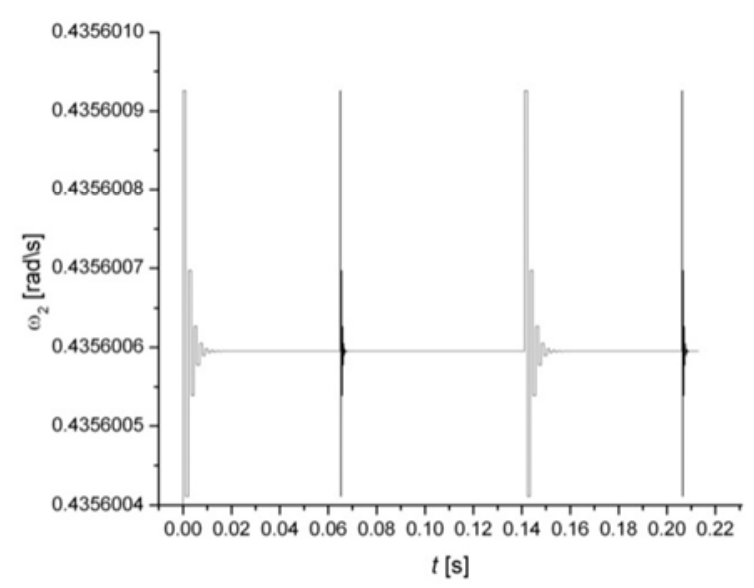

(a)

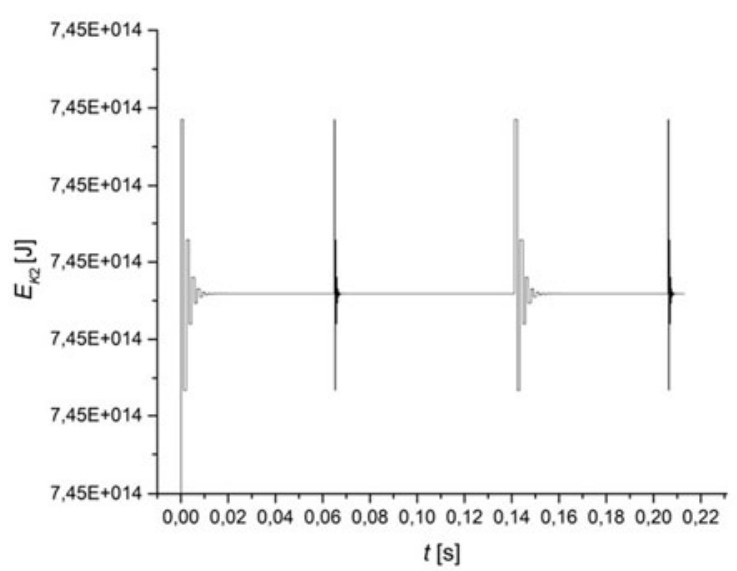

(b)

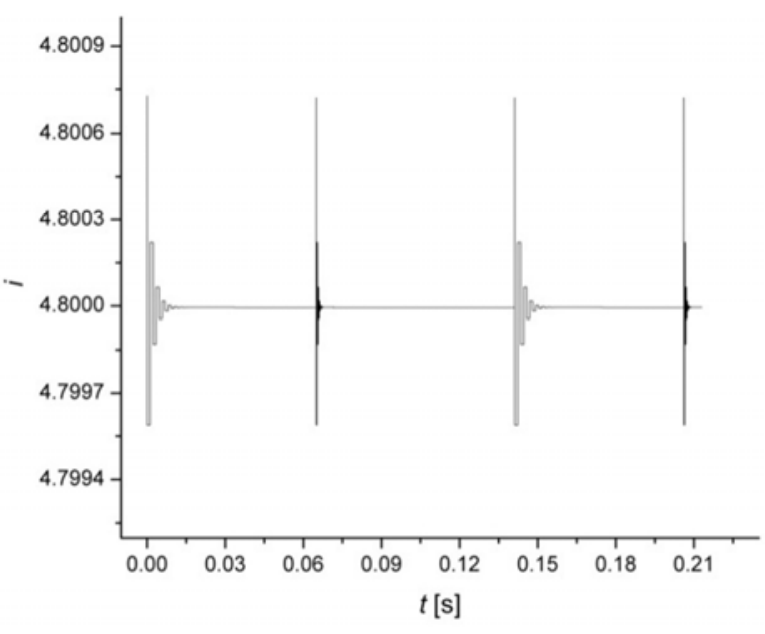

(c)

Fig. 3 The variations in the wheel angular velocity $\omega_{2}$ (a), kinetic energy of the wheel $E_{k 2}(\mathrm{~b})$ and transmission ratio $i$ (c), during two contact periods for the first spur gear pair given in Table $1(i=4.8$ and $k=5 / 9)$

The variation in the coefficient of restitution of the collision leads to the variation in the amplitude of vibro-impact vibrations. The amplitudes of all the studied variables decrease when the coefficient of restitution increases. In the cases of ideally elastic collisions (with $k=1$ ), the periodic repetition mode of vibro-impact dynamics stays "forever", and the coefficient of restitution of the collision has a character of the damping coefficient - when it increases, the amplitudes of all the studied variables decrease significantly.

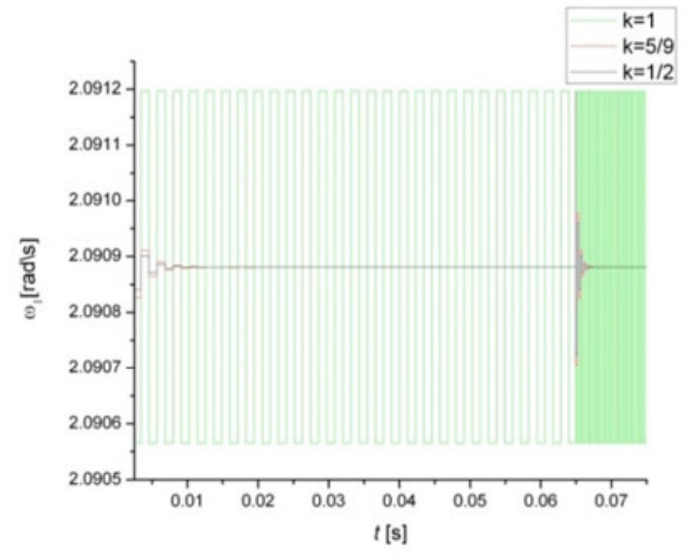

a)

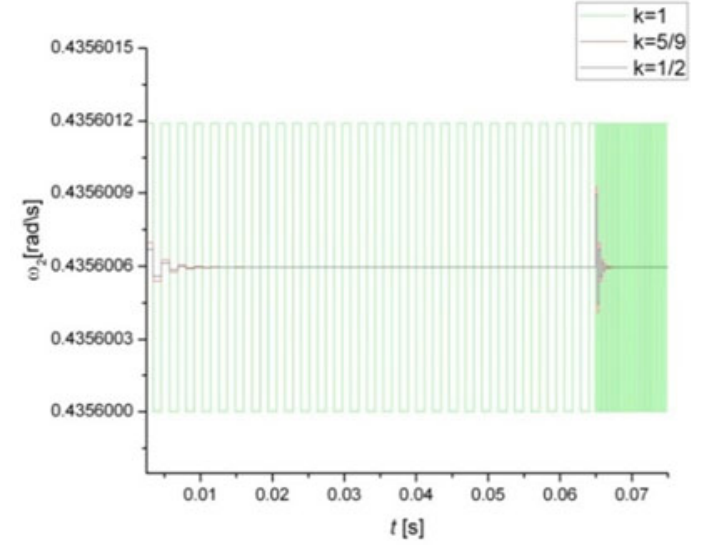

b)

Fig. 4 The variations in the pinion angular velocity $\omega_{1}$ (a) and the wheel angular velocity $\omega_{2}$ (b) during a contact period for different values of the coefficient of restitution of the collision 


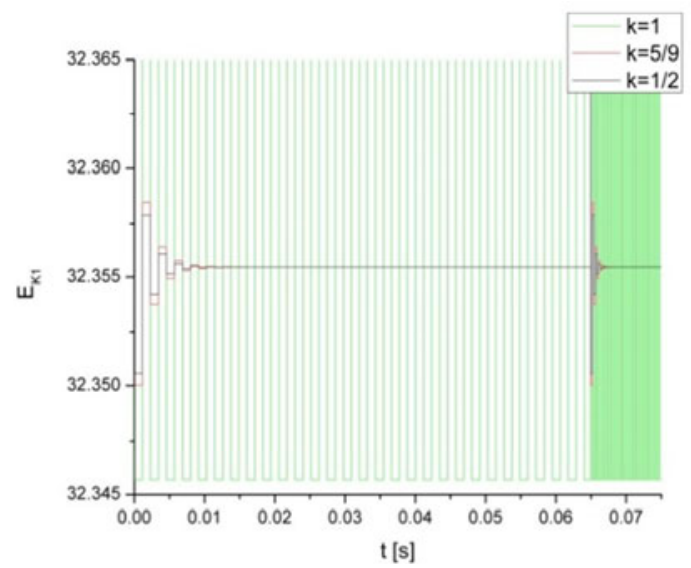

a)

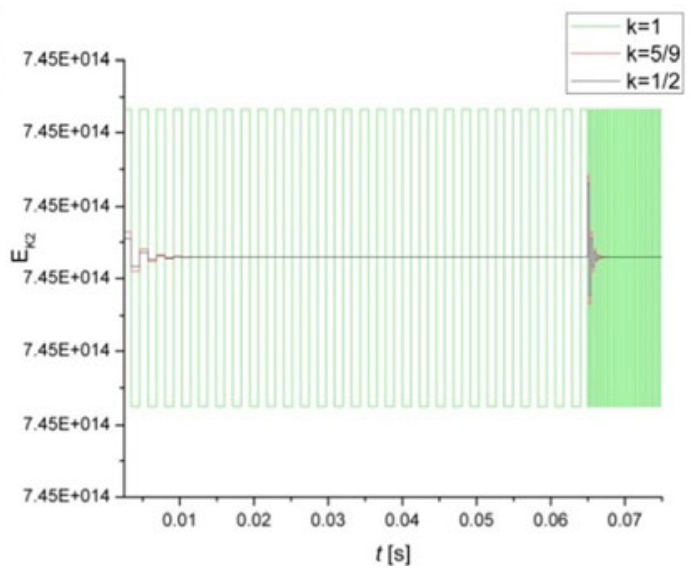

b)

Fig. 5 The variations in the kinetic energy of the pinion and the wheel $\left(E_{k 1}\right.$ and $\left.E_{k 2}\right)$ during a contact period for different values of the coefficient of restitution of the collision

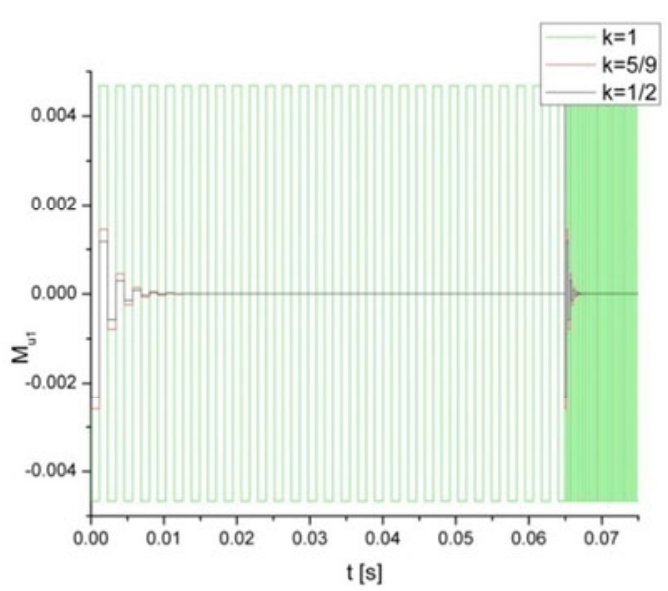

a)

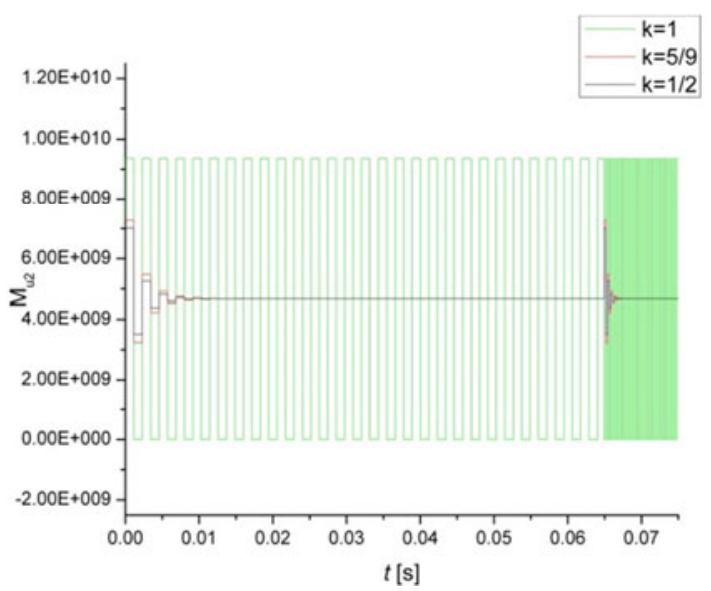

b)

Fig. 6 The variations in the pinion angular momentum $M_{u 1}$ and the wheel angular momentum $M_{u 2}$ during a contact period for different values of the coefficient of restitution of the collision

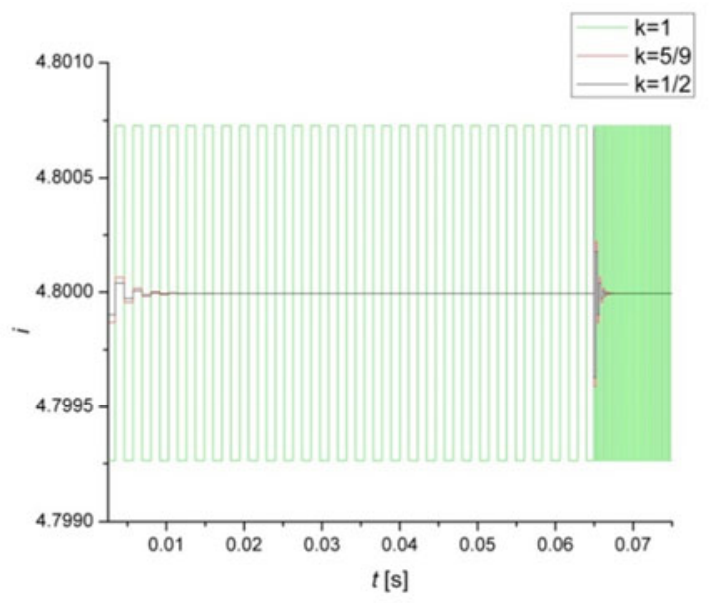

Fig. 7 The variations in the transmission ratio during a contact period for different values of $k$

\section{Discussion and Conclusions}

A new model for the investigation of vibro-impact dynamics of gears is developed, as the abstraction of a real system under corresponding assumptions, on the basis of approximation with two fictive rolling disks in successive centric central collisions. Within this model, the classical theory of impact is extended by the developed theory of kinematics and dynamics of the collision of two rolling axially symmetric rigid bodies. This extended 
theory is used for the determination of the outgoing angular velocities of the pinion and the wheel before and after every collision from a series of successive collisions, as well as before and after every successive forward-backward collision-impact between gear teeth.

The explained theoretical model of vibro-impact phenomenon in spur gears, as an approximate abstraction of the real vibro-impact system dynamics, has proved to be very suitable for the analyses of the dynamics of spur gears with such profile parameters and deviations that they lead to the backlash, the appearance of internal dynamic forces, and impacts.

By studying the analyses of the particular gear pair presented in this paper, the following conclusions can be drawn:

- Vibro-impact vibrations of spur gear pairs cause a significant variation in the main variables considered in the gear dynamics;

- A number of successive collision-impacts occurring during a very short time period lead to a decrease in the disturbance of angular velocity, but after a few impacts the disturbance is reduced, the regular operation regime is re-established and the gear rotates without vibro-impact vibrations. The ideal situation would lead to the repetition of this phenomenon to infinity. All of the described operation disturbances have only a character of vibro-impact vibrations but not of permanent disorders of angular velocities. However, a certain amount of energy is lost in these cases. Therefore, an extension of the new model developed and presented in this paper could be used for energy efficiency calculations.

- In the cases of ideally elastic collisions, the periodic repetition mode of vibro-impact dynamics lasts "forever" and would provoke a very high level of noise and vibrations;

- The coefficient of restitution of collision for an inelastic collision has a value smaller than 1. It is a parameter with a great impact on the vibro-impact vibrations of spur gears and has a character of damping coefficient - when it increases, the amplitudes of all the studied variables decrease.

\section{ACKNOWLEDGMENT}

Parts of this research were supported by the Ministry of Sciences and Technology of Republic of Serbia through Mathematical Institute of SASA, Belgrade and Faculty of Mechanical Engineering, University of Nis [Grant ON174001 and TR35029].

\section{REFERENCES}

[1] C. Spitas, V. Spitas, Coupled multi-DOF dynamic contact analysis model for the simulation of intermittent gear tooth contacts, impacts and rattling considering backlash and variable torque, Journal of Mechanical Engineering Science, Vol. 230, No.7-8, (2016) pp.1022-1047. https://doi.org/10.1177/0954406215596696.

[2] A. Andersson, L. Vedmar, A dynamic model to determine vibrations in involute helical gears, Journal of Sound and Vibration, Elsevier, Vol. 260, (2003) pp. 195-212.

[3] H. Moradi, H. Salarieh, Analysis of nonlinear oscillations in spur gear pairs with approximated modelling of backlash nonlinearity, Mechanism and Machine Theory, Vol. 51, Elsevier, (2012), pp. 14-31. https://doi.org/10.1016/j.mechmachtheory.2011.12.005.

[4] M. Amabili, A. Rivola, Dynamic analysis of spur gear pairs: steady-state response and stability of the sDOF model with time-varying meshing damping, Mechanical Systems and Signal Processing, Vol.11, No.3, Academic Press Limited, (1997) pp. 375-390.

[5] R. G. Parker, S. M. Vijayakar and T. Imajo, Non-linear dynamic response of a spur gear pair modelling and experimental comparisons, Journal of Sound and Vibration (2000), Vol. 237, No. 3, Accademic press, pp. 435-455, (2000). https://doi.org/10.1006/jsvi.2000.3067.

[6] I. Atanasovska, M. Vukšić Popović, Dynamics of gear pair systems with periodic varying mesh stiffness spur gears vs helical gears, Series: Scientific Review, Scientific and Engineering - Special Issue Nonlinear Dynamics S2 (2013) Dedicated to Milutin Milanković (1879-1958), Guest Editors: Katica R 
(Stevanović) Hedrih and Željko Mijajlović, YU ISSN:0350-2910, UDK 001, Publisher: Serbian Scientific Society, (2013) pp. 373-388.

[7] I. Atanasovska, The Mathematical Phenomenological Mapping in Nonlinear Dynamics of Spur Gear Pair and Radial Ball Bearing due to the Variable Stiffness, International Journal of Non-linear Mechanics, Elements of mathematical phenomenology and phenomenological mapping in non-linear dynamics, Edited by Katica R. (Stevanovic) Hedrih, Ivan Kosenko, Pavel Krasilnikov and Pol D. Spanos, Vol. 73, July 2015, Published by Elsevier, (2015) pp. 114-120. https://doi.org/10.1016/j.ijnonlinmec. 2014.11.015.

[8] M. Jelić, I. Atanasovska, The New Approach for Calculation of Total Mesh Stiffness and Nonlinear Load Distribution for Helical Gears, Mechanisms and Machine Science (Book Series), Series Ed.: Ceccarelli Marco, ISSN: 2211-0984, Vol. 13: Power Transmissions (Proceedings of The 4th International Conference on Power Transmissions - PT 12, June 20 - 23, 2012, Sinaia, Romania), Editor: G. Dobre, Publisher: Springer Science + Business Media Dordrecht 2013, (2012) pp. 645-654. https://doi.org/10.1007/978-94-007-6558-0_52

[9] D. Zhang, S. Wang, Parametric vibration of split gears induced by time-varying mesh stiffness, Proc IMechE Part C: J Mechanical Engineering Science, Published by Sage, UK, (2014) https://doi.org/10.1177/0954406214531748.

[10] S. Theodossiades and S. Natsiavas, Non-linear dynamics of gear-pair systems with periodic stiffness and backlash, Journal of Sound and Vibration, Vol. 229, No.2, Academic Press, (2000) pp. 287-310.

[11] Tengjiao Lin, H. Ou, Runfang Li, A finite element method for 3D static and dynamic contact/impact analysis of gear drives, Computer Methods in Applied Mechanics and. Engineering, Vol. 196, Elsevier, (2007) pp. 1716-1728. https://doi.org/10.1016/j.cma.2006.09.014.

[12] Song Xue, Ian Howard, Dynamic modelling of flexibly supported gears using iterative convergence of tooth mesh stiffness, Mechanical Systems and Signal Processing, Vol. 80, (2016) pp. 460-481. https://doi.org/10.1016/j.ymssp.2016.04.030.

[13] K. (Stevanović) Hedrih, Nonlinear phenomena in vibro-impact dynamics: central collisions and energy jumps between two rolling bodies, Nonlinear Dynamics, Vol. 91, No.3, Springer, (2018) pp. 1885-1907.

[14] K. Hedrih (Stevanović), Dynamics of Impacts and Collisions of the Rolling Balls, Dynamical Systems: Theoretical and Experimental Analysis, Springer Proceedings in Mathematics \& Statistics, Volume Number: 182, Chapter 13, Springer, ISBN 978-3-319-42407-1, (2016) pp. 157-168.

[15] K. Hedrih (Stevanović), Vibroimpact dynamics in systems with trigger of coupled three singular points: Collision of two rolling bodies, Book of Papers, International Congress of Theoretical and Applied Mechanics (ICTAM 2016), Montreal, Canada, from 21 to 26 August, 2016. IUTAM, PO.MS04-1.07.9, pp. 2019-2011. ISBN: NR16-127/2016E-EPUB; Catalogue Number: 978-0-660-05459-9 (2016)

[16] K. Hedrih (Stevanović), Vibro-impact dynamics of the rolling disks along rotate circle in vertical plane, Dynamical Systems, Control and Stability, Thematical Proceedings Editors: Jan Awewjcewicz, Marek Kazmierczak, Jerzy Mrozowski, Pawel Olejnik, 2015, Vol. 13/3, ISBN 978-83-7283-708-0, (2015) pp. 251-262.

[17] K. Hedrih (Stevanović)., From geometry, kinematics and dynamics of billiards to the extended theory of skew collision between two rolling bodies and methodology of vibro-impact dynamics (Review paper), Plenary Lecture, The 5-th international conference on "Nonlinear Dynamics" in Kharkov, September 2730, 2016, Dedicated to the 90th Anniversary of Academician V.L. Rvachov, Natiomal Techhnical University "Kharkov Polytechnic" et all., N49-Proceedings 538p, ISBN 978-966-97613-0-9, (2016) pp. 108-116.

[18] I. Atanasovska et al., Developing of gear FEM model for nonlinear contact analysis, Proceedings of 1. International Congress of Serbian Society of Mechanics, Kopaonik, 10-13.04.2007., ISBN 978-86909973-0-5. COBISS.SR-ID 138952460, published by Serbian Society of Mechanics, Belgrade, (2007) pp. 695-703.

[19] M. Ognjanović, Vibracije, šum i odstupanja mera zupčastih parova - istraživanje uzajamnih zavisnosti (Vibrations, noise and dimension deviations of gear pairs - research of dependences), $\mathrm{PhD}$ thesis, Faculty of Mechanical Engineering, Belgrade (in Serbian), 1984.

[20] I. Atanasovska et al., Explicit Parametric Method for Optimal Spur Gear Tooth Profile Definition, Advanced Materials Research, ISSN: 1022-6680, Vol. 633: Advances in Engineering Materials, Product and Systems Design (Special topic volume with invited peer reviewed papers only), Editor: Aleksandar Subić, ISBN-13: 978-3-03785-585-0, Trans Tech Publications, Switzerland, (2013) pp. 87-102. https://doi.org/10.4028/www.scientific.net/AMR.633.87. 
[21] S. Patil., S. Karuppanan, I. Atanasovska, A. Wahab., Contact Stress Analysis of Helical Gear Pairs, Including Frictional Coefficients, International Journal of Mechanical Sciences, ISSN0020-7403, Volume85, Published by Elsevier, https://doi.org/ 10.1016/j.ijmecsci.2014.05.013, (2014) pp. 205-211.

[22] M. Petrović, Elementi matematičke fenomenologije (Elements of mathematical phenomenology), Srpska kraljevska akademija, Beograd, 1911. str. 789. 1911.

[23] M Petrović, Fenomenološko preslikavanje (Phenomenological mapping), Srpska kraljevska akademija, Beograd, pp. 33 (in Serbian), 1933.

[24] M. Petrović, Mecanismes communs aux phenomenes disparates, Paris, 1921.

[25] D. Rašković, Mehanika III-Dinamika (Mechanics III-Dynamics), Naučna knjiga, Beograd, (in Serbian), 1965.

[26] G. Niemman, H. Winter, Maschinenelemente, Zweiter Band, Springer - Verlag, Berlin, 1989.

Submitted: $\quad 21.8 .2017$

Accepted: $\quad$ 15.3.2018
Assoc. R. Prof. Ivana Atanasovska iatanasovska@mi.sanu.ac.rs Mathematical Institute of SASA, Belgrade, Serbia

Full Prof. Katica (Stevanovic) Hedrih Mathematical Institute of SASA,

Belgrade, Serbia

Faculty of Mechanical Engineering, University of Nis, Serbia 